\title{
Hepatitis B-More Treatments, More Testing, Not Enough Data
}

\author{
Rena K. Fox, MD \\ Division of General Internal Medicine, University of California, San Francisco, San Francisco, CA, USA.
}

J Gen Intern Med 26(3):232-3

DOI: $10.1007 / \mathrm{s} 11606-010-1626-0$

(c) The Author(s) 2011. This article is published with open access at Springerlink.com

$\mathrm{C}$ hronic hepatitis B virus (HBV) infection has a much greater impact globally than in the US, yet even in the relatively low-prevalence US population, 1.25 million people are chronically infected, and an estimated $15-40 \%$ of those develop cirrhosis. ${ }^{1-3}$ Chronic HBV is less prevalent in the US than hepatitis $\mathrm{C}$ virus ( $\mathrm{HCV}$ ) infection, ${ }^{4}$ but the likelihood that patients with $\mathrm{HBV}$ will die from liver-related disease is much higher than with HCV. ${ }^{3}$ Furthermore, HBV has four phases of infection and a more variable natural history, with nonlinear, alternating progression of disease stages, ${ }^{5}$ making long-term management more complex and labor intensive. The modern era of HBV management now includes the use of quantitative tests of HBV DNA in initial diagnostic and routine long-term management, ${ }^{6}$ and the potential use of any of seven currently available HBV treatments. ${ }^{5}$ Although screening for HBV and appropriate vaccination for HBV still need increased attention and implementation, ${ }^{7}$ patients with established chronic HBV need lifelong monitoring, and this will generally be done in the primary care setting.

Published clinical guidelines, such as those from the American Association for the Study of Liver Diseases (AASLD), ${ }^{5}$ the US Treatment Algorithm, ${ }^{8}$ and the NIH Consensus Conference, ${ }^{9}$ offer recommendations as to the frequency of monitoring of ALT, HBV DNA, and HBeAg for different subgroups of chronic HBV patients. They also give recommendations as to when to initiate antiviral HBV treatment and guidelines as to the choice of drug or combination or drugs. Unfortunately there are several problems with these recommendations. For one, the recommendations are quite complicated. For example, for patients who are HBeAg positive and have ALT one to two times the upper limit of normal, the AASLD recommends monitoring the ALT every 3 months and monitoring the HBeAg every 6 months. However, if the patient is HBeAg positive but the ALT is less than the upper limit of normal, then they recommend monitoring the ALT every 3-6 months and monitoring the HBeAg every 6-12 months. For patients who are HBeAg negative with an ALT one to two times the upper limit of normal and HBV DNA between 2,000-20,000 IU/ml, they recommend checking the ALT every 3 months and the HBV DNA every 3 months. ${ }^{5}$ The purpose of this frequent monitoring is to determine when a patient may be transitioning from active to inactive phases of disease or vice versa, or when a patient would become eligible for antiviral treatment. However, the second and

Published online January 26, 2011 more significant problem with these guidelines is that there are no data to support the recommended frequencies for laboratory monitoring. While it is increasingly evident that ALT elevation and HBV DNA level are strong predictors of development of cirrhosis and $\mathrm{HCC},{ }^{10-12}$ the recommendations for indefinite monitoring of ALT, DNA, and HBeAg every 3 or 6 months have never been studied in any randomized trial or been compared to other frequencies, and there are no data to show that such frequent monitoring leads to an increased use of antiviral treatment or a mortality benefit. The third problem with the current guidelines is that long-term management with this frequency of complex monitoring is an ambitious charge for providers and patients. The intensity of the schedule requires a significant burden of both time and resources for both providers and patients. Finally, as for the guidelines for the use of treatment of HBV, while there are clinical trials to support benefits and safety of each therapy or combination of therapies, the endpoints in HBV treatment trials have largely been surrogate markers, such as suppression of HBV DNA, normalization of ALT, and seroconversion of HBeAg to anti-HBe. However, to date, no randomized controlled trials of anti-HBV therapies have demonstrated a beneficial impact on overall mortality, liver-specific mortality, or development of HCC.

In this issue of JGIM, two important papers (by Juday et al. and Shamliyan et al.) highlight two different but related questions needing attention in HBV management for general internal medicine. Juday and colleagues ${ }^{13}$ report on a retrospective cohort study examining whether US patients with chronic HBV are receiving laboratory monitoring of ALT and/or HBV DNA as guidelines recommend. The authors utilized a US health care claims database of almost 1,200 patients to investigate what proportion of chronic HBV patients had claims for ALT and/or HBV DNA monitoring. The authors looked for laboratory monitoring to have been performed at least once in a 12 -month period to assess adherence to clinical guidelines. They found that ALT monitoring is performed much more frequently than HBV DNA monitoring, and that if DNA monitoring is performed, mostly ALT is performed as well. But since only $35 \%$ of patients had been monitored in the year, this demonstrates the low implementation of the monitoring recommendations. Since annual laboratory monitoring is much less intensive than what some of the guidelines actually recommend, these results show an adherence rate that is actually higher than it would be if the authors looked for the every 3 months as recommended by some guidelines for the more active subgroups of HBV patients. What the study does not answer is whether such monitoring is beneficial. It begs the question, though, that if this population has approximately two thirds of the patients not being monitored at all in 1 year, will monitoring four times as often, up to every 3 months, as some groups recommend, ever be reasonable to expect? And more importantly, is the effort and cost for such monitoring actually worthwhile? These ques- 
tions still need to be answered if we are going to aim to adhere to such guidelines for long term management.

Also in this issue, Shamliyan and colleagues ${ }^{14}$ present a systematic review on the comparative effectiveness of antiviral treatments for chronic HBV. The authors show that there is no high quality evidence of the effects of antiviral HBV drugs on clinical outcomes. The study provides clinicians with needed comparative effectiveness data of hepatitis B treatments, but from clinical trials that are based on intermediate outcomes. Should we abandon HBV treatment since there are no data to show these desired outcomes? It is hard to justify completely holding off on using treatments that are available and show improvement in these intermediate markers, but future clinical trials should incorporate longer term outcomes to align treatment with the surrogate markers and whether the surrogate markers reflect important clinical outcomes.

It is true that primary care providers are not well enough informed about HBV monitoring and treatment. In 2010 the Institute of Medicine reported ${ }^{15}$ on the knowledge gap that exists in primary care on the subject of viral hepatitis and urged for this knowledge gap to be addressed. The primary care provider has the opportunity to have enormous impact on HBV by appropriately screening and identifying unknown infections, preventing transmission through education and targeted vaccination, and reducing the likelihood of the progression of liver disease because of HBV by counseling on alcohol reduction. Both papers in this issue ${ }^{13,14}$ provide much needed information on HBV, while at the same time, they both also highlight that before we aim to monitor patients intensively for the purpose of capturing them at the time that is best for treatment, we first need better evidence about whether frequent monitoring increases the use of treatment and whether HBV treatments provide benefit in progression to cirrhosis, HCC, and mortality. As we continue to make advances in the care of patients with hepatitis B, we must ask for the data behind the guidelines before we decide the guidelines are right for us.

Open Access: This article is distributed under the terms of the Creative Commons Attribution Noncommercial License which permits any noncommercial use, distribution, and reproduction in any medium, provided the original author(s) and source are credited.
Corresponding Author: Rena K. Fox, MD; Division of General Internal Medicine, University of California, San Francisco, 1545 Divisadero St., Ste 307, San Francisco, CA 94143-0320, USA (e-mail: rfox@medicine.ucsf.edu).

\section{REFERENCES}

1. McQuillan GM, Coleman PJ, Kruszon-Moran D, Moyer LA, Lambert SB, Margolis HS. Prevalence of hepatitis B virus infection in the United States: the National Health and Nutrition Examination surveys, 1976 through 1994. Am J Pub Health. 1999;89:14-8.

2. CDC. Recommendations for Identification and Public Health Management of Persons with Chronic Hepatitis B Virus Infection. MMWR 2008; 57 (No. RR-8)

3. Lavanchy D. Hepatitis B virus epidemiology, disease burden, treatment, and current and emerging prevention and control measures. J Viral Hepat. 2004;11:97-107.

4. Armstrong GL, Wasley A, Simard EP, McQuillan GM, Kuhnert WL, Alter MJ. The prevalence of hepatitis C virus infection in the United States, 1999 through 2002. Ann Intern Med. 2006;144:705-14.

5. Lok AS, McMahon BJ. Chronic hepatitis B: Update 2009. Hepatology. 2009;50(3): 1-36.

6. Gish RG, Locarnini SA. Chronic hepatitis B: current testing strategies. Clin Gastroenterol Hepatol. 2006;4:666-76.

7. Heathcoate J. Demography and presentation of hepatitis B infection. Am J Med. 2008;121:S3-S11.

8. Keeffe EB, Dieterich DT, Han SH, et al. A treatment algortithm for the management of chronic hepatitis B virus infection in the United Staes: 2008 update. Clin Gastroenterol Hepatol. 2008;6:1315-41.

9. NIH Consensus Development Conference Statement on the Management of Hepatitis B NIH Consensus and State-of-the-Science Statements, Volume 25, Number 2. October 20-22, 2008

10. Chen CJ, Yang HI, Su H, et al. Risk of hepatocellular carcinoma across a biological gradient of serum hepatitis B virus DNA level. JAMA. 2006;295:65-73.

11. Iloeje UH, Yang HI, Su J, Jen CL, You S1, Chen CJ. Predicting cirrhosis risk based on the level of circulating hepatitis B viral load. Gastroenterrology 2006; 13-0: 678-86

12. Iloeje UH, Yang HI, Jen CL, et al. Risk and predictors of mortality associated with chronic hepatitis B infection. Clin Gastroenterol Hepatol. 2007;5:921-31.

13. Juday T, Tang H, Harris M, Powers AZ, Kim E, Hanna, GJ. Adherence to chronic hepatitis B treatment guideline recommendations for laboratory monitoring of patients who are not receiving antiviral treatment. JGIM.

14. Shamliyan TA, Johnson JR, MacDonald R, et al. Comparative effectiveness of antiviral treatments for chronic hepatitis B infection, systematic review of the literature. JGIM.

15. Institute of Medicine. Hepatitis and Liver Cancer. A National Strategy for Prevention and Control of Hepatitis B and C. Accessed at : http:// www.iom.edu/Reports/2010/Hepatitis-and-Liver-Cancer-A-NationalStrategy-for-Prevention-and-Control-of-Hepatitis-B-and-C.aspx on December 20, 2010 